\title{
La metamorfosis del trabajo y los procesos de activación
}

The metamorphosis of work and processes of activation

\begin{abstract}
José Pablo Bentura
Doctor en Ciencias Sociales (FLACSO). Docente investigador del Departamento de Trabajo Social de la Facultad de Ciencias Sociales de la Universidad de la República — Uruguay. <pbentura@gmail.com>
\end{abstract}

\begin{abstract}
Alejandro Mariatti
Máster en Trabajo Social. Docente investigador del Departamento de Trabajo Social — Facultad de Ciencias Sociales Universidad de la República — Montevideo, Uruguay <alejandromariatti@gmail.com>
\end{abstract}

Resumen: La presente comunicación es un primer avance de la investigación "La activación como estrategia de combate a la pobreza..." en curso. Los autores sostienen, a partir de un análisis socio-histórico de los procesos de transformación en el mundo del trabajo marcado por la ofensiva del capital sobre las conquistas del trabajo, los discursos y prácticas que apuntan a la activación como estrategia de combate al desempleo y la pobreza son consistentes y solidarios con la ofensiva mencionada.

Palabras clave: Trabajo. Desempleo. Activación. Neoliberalismo. Individualización.
Abstract: This communication is a first step in the research "Activation as a strategy to fight against poverty..." in progress. From a socio-historical analysis of the processes of transformation in the world of work, the authors argue that, in this regressive context, marked by the advance of capital over the conquest of work, discourses and practices that point to the activation. As a strategy to combat Unemployment and poverty are consistent and in solidarity with the mentioned advance.

Keywords: Work. Unemployment. Activation. Neoliberalism. Individualization.

\section{Presentación}

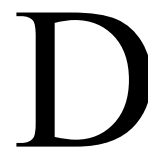
elimitar los trazos que definen nuestra contemporaneidad implica establecer el conjunto de particularidades que le dan identidad y visualizar el momento histórico en que estas particularidades comenzaron a configurarse de forma a dar inicio a una época. En este sentido, 
hablar de contemporaneidad supone remitirse a la crisis de los años setenta, pero sobre todo, a la forma de enfrentar la crisis que reorientó al capital para recuperar la tasa de lucro.

Como forma de legitimar esta forma de enfrentar la crisis, se pretendió establecer que era la única, inexorable y natural forma de hacerlo. En sus orígenes esta estrategia fue rotundamente ineficaz y resultó en una decidida y unánime resistencia que el movimiento social opuso a la implantación de este modelo de resolución. Represión salvaje, dictaduras militares, persecución a personas y organizaciones populares, fueron la antesala de la imposición de esta forma de enfrentar la crisis.

Doblegar toda la resistencia fue la condición sine qua non para que, finalmente, la idea de que la respuesta a la crisis era la única, inexorable y natural, tuviera alguna capacidad para legitimar el ajuste estructural que avanzó sobre todas las conquistas obreras que significaron más de cien años de combate.

La intención de este artículo es, en primer lugar, presentar el proceso de ofensiva del capital sobre todas las conquistas obreras a través de un mecanismo clásico, sustituir masivamente trabajo vivo por trabajo muerto de modo a impactar sobre la garantía de pleno empleo. Está ofensiva contó con la complicidad de gobiernos como el de Ronald Reagan en Estados Unidos y Margaret Tacher en Inglaterra y las dictaduras militares en América Latina que, con el único argumento de la represión, desregularon los controles estatales que eran la base de esa garantía, dejando sin sustento la posibilidad de aquellas conquistas.

$\mathrm{Y}$ en segundo lugar, busca mostrar cómo, a partir de la ofensiva del capital sobre las conquistas del trabajo, se produce una crisis de integración social dramática. En otros términos, la aplicación del ajuste estructural genera problemas permanentes, y la crisis de integración social no es apenas "el dolor de parto" de la imposición del nuevo modelo, como pretendían los discursos neoconservadores y neoliberales, por tanto era preciso resolver estos problemas permanentes adaptando el sistema de protección social a la nueva realidad. 
Sin eufemismos: adaptar el sistema de protección social a la nueva realidad significa destruir el sistema de protección social y sustituirlo por mecanismos de encuadramiento o represión para los que no aceptan condiciones miserables de reproducción social. Cada individuo atomizado, buscando las mejores condiciones de reproducción social y, para quienes fracasan, programas de integración sui generis donde el discurso de la activación es el recurso mágico con que se pretende resolver ese fracaso. El análisis de estos mecanismos de encuadramiento se centrara en el caso uruguayo. Por último, como es de uso, se expondrán algunas reflexiones finales.

\section{Reestructuración productiva, el retorno del verdadero rostro del capital}

No sería una novedad, pero sí una premisa necesaria como marco de nuestra reflexión, la interpretación de que "La producción capitalista no es ya la producción de mercancías, sino que es, sustancialmente, producción de plusvalía" (Marx, 1978, p. 425). En resumen, dentro del orden burgués, solo es productivo aquel obrero que produce plusvalía y hace rentable el capital.

La reproducción de la vida de los asalariados significa el mantenimiento del capital variable, indispensable para la acumulación de capital. "Y, si bien hay que proteger a los obreros de la muerte por hambre, no se les debe dar nada que valga la pena ser ahorrado" (Marx, 1978, p. 519).

El corto siglo XX al decir de Hobsbawm (1995) pareció querer corregir la plana de Marx, en verdad apenas pudo lograrlo durante tres décadas. A partir de fines del siglo XIX, el capital monopólico reorientó las funciones del Estado. Ya no se precisaba solo un Estado que garantizara la propiedad privada y las condiciones para la reproducción del orden, sino que el capital monopólico ahora necesitaba de un Estado con la función activa de garantizar los lucros del capital monopólico. "La necesidad de una nueva modalidad de intervención del Estado se deriva principalmente (...) de la demanda (...) de un vector extra económico para asegurar sus objetivos estrictamente económicos" (Netto, 1996, p. 21). 
La intervención extra económica del Estado propia del estadio de los monopolios, es contemporánea con un movimiento obrero con capacidad de organización y lucha en todos los planos de la sociabilidad, sindicatos con capacidad de movilización y negociación, partidos de clase con una relevante expresión electoral, espacios de formación y difusión ideológica etc. En este contexto, "el capitalismo monopolista por sus dinámicas y contradicciones (...) al buscar legitimidad política en el juego democrático" (Netto, 1995, p. 25) comienza a hacer concesiones a las clases subalternas, las luchas obreras comienzan a tener éxito en obtener conquistas parciales pero que a lo largo de la primera mitad del siglo XX llegaron a constituir los Estados de Bienestar.

En los años 1970, se procesó una crisis de nivel planetario que tuvo como resultado una ofensiva radical del capital contra todas y cada una de las conquistas obreras logradas hasta ese momento. Para Antunes, la segunda mitad del siglo XX ha significado un periodo de degradación del trabajo (Antunes, 2009, p. 29). En los años 1970, cuando la crisis se desató, las regulaciones extra económicas que funcionaban como mediación política y eran el resultado de conquistas políticas de "la-clase-que-vive-de-su-trabajo" (Antunes, 1998) fueron puestas en tela de juicio.

Por un lado, el discurso neoconservador explicaba la crisis en dos palabras: pérdida de autoridad. El Estado había perdido su autoridad y era capturado por los intereses corporativos, que le reclamaban de forma "irresponsable" cada vez más beneficios como si fuera un "barril sin fondo". Por el otro se ofrecía la solución, había que desempolvar la ya vieja ideología neoliberal y destruir cualquier regulación extra mercado para que el Estado recuperara sus naturales funciones: garantizar la propiedad privada y a lo sumo auxiliar, por razones humanitarias, a los incompetentes que fracasan en el mercado, garantizándoles la vida e incorporándoles competencias para que no vuelvan a fracasar.

La ideología neoliberal da una exclusiva explicación individual a la pobreza, como un fracaso personal, cada trabajador debe demostrar sus capacidades de sostenerse como mercancía vendible. Esa fue quizá la mayor privatización: explicar el desempleo como falta de capacidades personales, es decir: el desempleo es un problema privado de quien lo padece. 
Las transformaciones en el mundo del trabajo generan niveles crecientes de desempleo, que en los modelos bismarkianos reduce la cantidad de aportantes a la Seguridad Social, y que desencadenan en una lógica pro-cíclica la reducción de las exigencias al capital por parte de los Estados, reducción de impuestos, menores controles y reglamentaciones etc. El llamado proceso de flexibilización trae de la mano la desfinanciación de los Estados Sociales (Hobsbawm, 1995, p. 393-394).

La reestructuración productiva no debe ser pensada como el resultado inexorable del avance tecnológico; es resultado directo de la ruptura del pacto interclases (Przeworski, 1995) y opera directamente sobre la posibilidad de garantizar pleno empleo (Antunes, 1998) erosionando la eficacia política de los seguros sociales que eran el dispositivo material sobre el que se asentaba el "bienestar" como la promesa contenida en el ideal de progreso. Una de las principales rupturas que se generaron a partir de la reestructuración productiva fue el nexo que, establecía automáticamente el sentido común, entre avance tecnológico y progreso, entendido este como el desarrollo del bienestar de la humanidad (Netto, 2012).

A partir de ello, se comenzó a implementar una serie de experimentos (Bentura; Vecinday, 2011) que pretenden atender este fenómeno devenido en carencia educativo laboral. Es decir, el ocaso de la empresa taylorista/ fordista motivó un nuevo orden destinado a garantizar la acumulación de modo cada vez más flexible, sustituyendo el trabajo vivo por tecnología, de allí que el autor identifica esta flexibilización como "liofilización” (Antunes, 2009, p. 30).

Sin lugar a dudas, "la revolución informacional" (Lojkine, 1995) tuvo mucho que ver en este proceso, sobre todo y primero como desarrollo de la industria bélica y la demanda del complejo militar norteamericano a finales de la Segunda Guerra Mundial. Su aparición es "una condición material esencial para la elevación de la productividad del trabajo en todas las esferas de la vida" (Lojkine, 1995, p. 50).

Si se nos concede la posibilidad de establecer comparaciones, la automatización de fines de siglo XX es un proceso muy similar a aquél vivido en la época del maquinismo de la revolución industrial. 
La diversificación de la división del trabajo, el aumento de la productividad desde el ahorro de trabajo vivo (Gorz, 1982; Offe, 1995; Castel, 1997; Antunes, 1998, 2000, 2009; Lessa, 2011) y la ampliación de los mercados, adquirió un rumbo de alcance mundial con proceso de desterritorialización, acompañado de una tendencia al surgimiento de capital volátil y especulativo. El escenario laboral, aun en momentos de baja del desempleo, presenta el surgimiento de una escala minoritaria de trabajadores especializados y adaptados a estas transformaciones contemporáneas, acompañado de muchas nuevas ramas de trabajadores devenidos en polivalentes y multifuncionales.

También se consolidó una gran masa de trabajadores descalificados a partir de una creciente reducción del proletariado fabril estable; incremento del nuevo proletariado, creación de un subproletariado fabril y de servicio (trabajadores tercerizados, subcontratados, part-time, muchos empleados de supermercados, guardias de seguridad y personal doméstico.

Este proceso en donde el ultra calificado hoy puede ser precarizado mañana (Antunes, 2009, p. 33) es el escenario estructural como condición, pero desestructurante como síntoma para los trabajadores. Pero esto no se detiene allí. Adquiere relevancia una dimensión personal desde la convocatoria espiritual o compromiso subjetivo.

Una dimensión cognitiva ahora apropiada por la empresa y convocando al trabajador de forma activa desde un compromiso subjetivo y una responsabilización por el desenlace concentrador propio de la producción capitalista. Al secuestro permanente de saberes trasladados a la maquinaria para aumentar la productividad del trabajo humano, se suma ahora la convocatoria desde su compromiso personal con los objetivos y la misión de la empresa. Una doble "actitud" en favor de un interés "común". Una nueva convocatoria para un proceso que sigue cumpliendo una función decisiva en la creación de valores de cambio.

La metamorfosis del mundo del trabajo (Antúnes, 1995) vía liofilización, significó el quiebre de la "sociedad salarial" (Castel, 1997), acorralando a los sistemas mutuales y promoviendo un abordaje dual en la asistencia (Aust et al., 2004). El sistema mutual de la "edad de oro" (Hobsbawm, 1996) se 
desequilibra y motiva una serie de nuevos experimentos (Bentura; Vecinday, 2011). El quiebre de la sociedad salarial es el principio para el surgimiento de "desafiliados", "inútiles para el mundo" (Castel, 1997) y su presencia pone en duda la "cohesión social" (Durkheim, 2001).

Al combinar la desproletarización con la subproletarización, surge la sociedad dual. El pauperismo ahora como expresión del desempleo estructural propio del ajuste neoliberal, se convierte en blanco de los programas de "combate a la pobreza". El desempleo es atendido con focalización, como si se tratara de un fenómeno personal, particular, individual.

La retórica neoliberal, privatista, individualizadora, supone un nivel de actividad individual como "remedio" para esta enfermedad llamada crisis. La actitud del desempleado o del asistido será la llave para el éxito. Un proceso de individualización "biográfica" frente a un determinismo mundial casi "anónimo". "El individuo es llamado a ser el señor de su destino cuando todo parece estar fuera de su control” (Mitjavila, 2004, p. 74).

\section{Respuestas minimalistas individuales para grandes problema sociales}

En relación a la atención al desempleo, en Uruguay, a partir de los años 1990, comenzó a construirse un espacio para la reconversión laboral del trabajador desempleado. Ahora que el ajuste no permite generar obra pública, como en tiempos de la crisis de 1929 (Jacob, 1983, 1981) y la integración ya no puede resolverse vía pleno empleo, surge una atención personal, como batería de nuevos recursos, que mejoren el desempeño laboral individual en un nuevo escenario post crisis de fin de siglo.

En la salida de la dictadura, Uruguay registró altos niveles de dependencia del ingreso de capitales externos (Astori, 1983) y los niveles de pobreza llegaban a al 46,2\% de la población (Midaglia; Antía, 2007, p. 138). Esta pobreza promovida por el ajuste comienza a ser entendida y atendida como problema individual.

Se intensificaron los vínculos comerciales con el mundo, promoviendo la profundización de una economía liberalizada al mercado mundial y 
regional, lo que condicionó la competencia de industrias crecidas por la sustitución de importaciones. A a pesar de este deterioro, "(...) se crearon condiciones excepcionales para la incorporación de equipos y tecnología" (Supervielle; Pucci, 2008, p. 92). Fue el inicio para una reducción de costos y el aumento de productividad.

Estas transformaciones impactaron en la organización del trabajo y la composición de la fuerza, donde se notó la necesidad de una mejor formación. “(...) se verificó una tendencia a la disminución de los puestos de trabajo y al desplazamiento de los trabajadores" (ver Supervielle; Pucci, 2008, p. 93). Como ejemplo, “(...) la industria manufacturera, perdió 65.669 puestos de trabajo entre 1990 y 1998 , reduciendo un $39 \%$ su capacidad de contratación y perdiendo 80 millones de horas trabajadas en 8 años" (Olesker, 2001, p. 54).

Durante los años 1990, pleno auge del Consenso de Washington será creada en Uruguay la Junta Nacional de Empleo, en el marco del Ministerio de Trabajo y Seguridad Social (MTSS). La misma, será el ámbito institucional para la creación de un nuevo abordaje al problema del desempleo. Desde allí, se comenzarán a implementar diferentes programas de atención al trabajador desempleado por la crisis, desde la capacitación y la reconversión a partir de la educación laboral.

Esta creación es para nosotros el inicio de programas con características y componentes de "activación" a los desocupados, con una doble acepción:

i) Porque se espera una nueva actitud del participante, no solo en el desempeño de un empleo efectivo, sino también y sobre todo, en la actitud y el protagonismo cuando como educando se lo convoca para procesos de aprendizaje en la búsqueda del nuevo empleo, entrenándolo para el desarrollo de estrategias de presentación y entrevistas, como vendedor de sus nuevos saberes, ingresando a un infinito proceso - en sentido kafkiano - de reconversión laboral. Infinito, porque la recomposición productiva post crisis, no ha resuelto nada, sino que está caminando sobre la decreciente tasa de lucro y necesita de una recomposición permanente.

ii) Porque también la idea de "activar" o "activación”, cargar de activos (en el sentido contable), como ampliación de habilidades y conocimientos 
que mejoraran las posibilidades de venta de trabajo al nuevo mercado mundial de trabajo, flexible, precario, intermitente e impermeable a la acción reguladora del Estado. Por lo tanto, en un diálogo fecundo, la actitud y los nuevos saberes, son la forma en cómo se procesa de individualización en la atención al desempleo, vía la activación como explicación fetichizada, que utilizando el ropaje del fracaso personal, legitima el avance del ajuste del capital sobre el trabajo.

Las teorías sobre los capitales individuales como "capital humano", tanto a nivel de la teoría mundial (Schultz, 1992; Hayek, 1937) como regional (Katzman, 2001), albergan una explicación personal del desempleo en tanto carencia propia que reduce las probabilidades de aprovechamiento de oportunidades del mercado (Pino Freire et al., 2010). La consecuencia lógica de este diagnóstico es que la ampliación de éste tendría un efecto contrario. 'Se lucha contra la 'dependencia' de los sujetos, pero el objeto en torno al cual se problematiza la relación no es la dependencia del mercado sino la dependencia del Estado" (Crespo et al., 2009, p. 96).

En este sentido, la reconfiguración de la atención al desempleo, por medio de un abordaje sobre el cambio actitud y el acceso a nuevos conocimientos, supone la exclusividad del individuo como responsable de la metamorfosis del mundo del trabajo contemporáneo.

Cuando elegimos analizar los programas destinados a desempleados-que-buscan-empleo en Uruguay, notamos que contemplan en su propuesta dispositivos que suponen la necesidad de ampliar el "capital humano". Se implementan desde una división entre: a) saberes específico-instrumentales sobre alguna técnica para desplegar un oficio y b) saber transversal, saber previo o genérico, búsqueda y mantenimiento de un empleo. El primero, se pone a prueba cuando se ejerce el oficio y el segundo se refiere a la actitud del sujeto, a sus hábitos, a la intimidad de su moral y sus valores, la docilidad necesaria para aceptar la relación de dominación asalariada en su renovada variedad post crisis en la heterogénea versión que resuelve la recomposición de la tasa de lucro.

En particular, si revisamos cual fue el impacto que tuvo la metamorfosis laboral post crisis en Uruguay desde los dispositivos que atienden el 
desempleo como un problema, notamos no solamente como la activación es parte de la batería de acciones, sino como a su vez se ensambla con procesos de focalización y dualización, conformando una serie de programas destinados a trabajadores inempleables. Porque, a partir de la creación del Ministerio de Desarrollo Social (MIDES), se ha implementado una nueva serie de programas de Inserción Socio-Laboral (ISL), con una Dirección llamada "de Economía Solidaria e Inserción Socio-Laboral". Esto será entendido para nosotros como una dualización, en el sentido de abrir un espacio nuevo para atender un problema ya existente. El nuevo MIDES se agrega a la gestión del MTSS.

En Uruguay la nueva estrategia dual de atención al desempleo, combina dos grandes espacios entre el MTSS y el MIDES, con una estrecha relación entre los saberes previos y la experiencia laboral que portan los sujetos participantes antes de ingresar a un programa y el protagonismo que toma al interior del programa alguno de estos saberes. El nuevo Ministerio absorberá, como nueva problemática a esta nueva población pauperizada propia del ajuste de fin de siglo.

A medida que el candidato está más próximo a situaciones de pauperismo, más tiempo fuera del mercado formal de empleo y con menos años de escolaridad, aumenta el protagonismo de componentes de capacitación transversal con mayor presencia de componentes disciplinadores y moralizantes en desmedro de saberes específico-instrumentales, lo que genera una capacitación mínima que por momentos se vuelve ficticia para el mercado de trabajo (Daroqui, 2016).

La mundialización de la economía modificó el escenario del mercado de trabajo y la característica de las nuevas soluciones al problema del desempleo han ganado hegemonía en torno a construir este problema como una responsabilidad personal, imponiendo una nueva modalidad que tiende a responsabilizar a los individuos de esta modificación planetaria. La preocupación por ampliar los conocimientos de los desempleados se tornó un lugar común en las nuevas propuestas de fin de siglo XX y la "activación" significó la estrategia para resolver el desencuentro entre las necesidades de la explotación y el trabajo. 
En particular para Uruguay, una nueva mirada al problema ingresa a partir de la creación de programas en un nuevo Ministerio, como forma de ubicar características de un "nuevo problema".

La decisión de crear un ministerio para administrar políticas asistenciales, focalizadas, gestionadas por la "sociedad civil organizada" parece estar respondiendo a que la exclusión social es subproducto inevitable de la política de desarrollo "posible" a implementar, y que la nostalgia del Uruguay mesocrático, no es otra cosa que un lastre del pasado del que es necesario desembarazarse para ponerse a construir el Uruguay del futuro.

Los programas apuntan al alcanzar transformaciones en los comportamientos de la población beneficiaria con la finalidad de mejorar sus posibilidades de inserción en el mercado, espacio éste que aparece naturalizado como escenario donde se procesa la verdadera integración social.

La salida de la pobreza reside en mejorar las capacidades económicas del eslabón más débil de la cadena, los propios pobres. Para ello, se propone la potenciación de los recursos del capital social y activos humanos de las familias pobres, generar capacidades de realización de emprendimientos microempresariales. La mejora en capital social y humano contribuiría para que los propios pobres manejen mejor los riesgos imprevistos (como crisis económicas, desastres naturales, epidemias etc.), se reinserten en la economía y se beneficien de las oportunidades del mercado (Serna, 2007, p. 4-5).

La preocupación central del MIDES, expresada hasta el cansancio por los operadores tecnopolíticos, fue recogida en entrevistas realizadas en 2005. Expresaba que el principal objetivo de todo el sistema de programas del MIDES, apuntaba a mejorar las condiciones de empleabilidad de la población objetivo. De algún modo se expresaba que la preocupación central radicaba en convertir las políticas asistenciales pasivas en políticas activas o de activación.

Porque no genera empleo genuino, [se refiere al programa Trabajo por Uruguay] porque impacta en el nivel de empleabilidad, si la gente mejora su autoestima sale con mejores condiciones a buscar empleo, con mejores 
herramientas: técnicas de búsqueda de empleo, derechos laborales, un sin fin, $\mathrm{y}$ aparte porque internamente las incorpora y se apropia de modo distinto de su búsqueda de empleo (entrevista a Directora Política del MIDES ${ }^{1}$ ).

Un elemento sustancial de toda la nueva programática implementada por el MIDES es la convicción de que la intervención estatal debe operar sobre los individuos y no sobre el mercado, los programas deben operar sobre aspectos individuales y no sociales, la intervención no es para generar empleo, no se considera legítimo crear nuevos empleos, sino operar sobre la "empleabilidad" esto supone toda una perspectiva política, el problema es el sujeto, su autoestima, su disponibilidad a buscar empleo de otra forma.

La gente quiere ir a trabajar, hemos tenido infinidad de problemas, pero en el $90 \%$ de las evaluaciones tenemos que todo el mundo trabaja, todos trabajan, les quedará mejor o peor pintada la pared pero todos trabajan. Y esto es doblemente valioso en las mujeres, porque todas tienen muchos hijos, porque no es decir me anoto y trabajo, primero hay que ver qué hago con los niños, supone toda una movida familiar para ver quién se hace cargo de los niños, es doble compromiso con la tarea, después habrá que enseñarles muchas cosas sobre el código del trabajo, sin duda pero la motivación está (entrevista a Directora Política del MIDES²).

Pero la activación no puede reducirse apenas al trabajador, que según dice la operadora tecnopolítica ya está activado, quiere trabajar y trabaja, la activación busca operar sobre toda la población para ofrecer al capital una población bien dispuesta para el trabajo, pero que además cuenta con todo un sistema comunitario que sostiene a ese trabajador como una mercancía disponible de forma inmediata para su consumo, detrás del trabajador o la trabajadora hay toda una comunidad activada para sostener a ese trabajador bien dispuesto en el anaquel para su consumo inmediato, alguien se hará cargo

1. Entrevista realizada por el autor en la investigación para su tesis doctoral en 2010 (Bentura, 2011).

2. Entrevista realizada por el autor en la investigación para su tesis doctoral en 2010 (Bentura, 2011). 
de las condiciones necesarias para la reproducción de la fuerza de trabajo, toda la familia esta activada, toda la comunidad esta activada.

\begin{abstract}
Que vas a enseñar con 20 a 30 horas, el viejo problema de la UTU que enseñan con un torno viejo y después se vuelve obsoleto. Sin embargo las transversales le quedan para toda la vida, trascienden la intervención: si le enseño a trabajar, si le marco que si llega tarde en un empleo formal le descuentan y al tercer día tiene una observación y al cuarto una suspensión, le marco lo que es la vida real del mercado de trabajo a través del trabajo, después lo re-trabajo en un taller colectivo: cómo se sintieron la primera semana de trabajo, cómo bancaron las jerarquías aunque no le gustaran, cómo se llevaron con el de al lado, todo lo actitudinal del trabajo, eso le va a quedar (entrevista a Directora Política del MIDES ${ }^{3}$.
\end{abstract}

Es notable la configuración interpretativa en que organiza su reflexión la operadora tecnopolítica, en primer lugar la condena sin matices ni dudas, las políticas universales son inevitablemente ineficientes, la UTU, tradicional escuela de oficios del Uruguay, enseña cosas inservibles, la formación técnica es descalificada frente a la siempre útil moralización y disciplinamiento, el toque final de esta mercancía disponible para el capital, moralizada, disciplinada y con las actitudes necesarias para que el capital se ahorre todo ese trabajo desagradable de disciplinar a la fuerza de trabajo.

\title{
Reflexiones finales
}

Las alteraciones en el mundo del trabajo y la transformación del Estado para atender apenas las manifestaciones más agudas de la cuestión social tienen como consecuencia inmediata la pérdida de conquistas históricas del movimiento obrero, esto como es lógico no representa una cuestión de dignidades, representa una catástrofe social, las condiciones de vida de la

3. Entrevista realizada por el autor en la investigación para su tesis doctoral en 2010 (Bentura, 2011). 
clase trabajadora se ven afectadas dramáticamente, los sectores "integrados" pagan un fuerte tributo para mantener esa condición, inestabilidad, pérdida de derechos, aumento de sus jornadas laborales, el ingreso de las mujeres al mercado laboral no representó una mejora en las condiciones de vida de las familias etc.

Pero aquellos expulsados del mundo del trabajo y aquéllos que mantienen una relación precaria con este viven en condiciones de vida indignas, el pauperismo retorna bajo la forma del precariado.

La administración de la cuestión social sufre, entonces, una alteración sustancial, la solidaridad entendida como el lazo vinculante entre individuos interdependientes se enfrenta a la existencia, aparentemente irreductible, de contingentes humanos, que son visualizados como "inútiles al mundo". La tarea de los Estados Sociales - garantizar el pleno empleo y desarrollar políticas tendientes al bienestar de la población - se trasmutan en la necesidad de garantizar la integración social en una sociedad donde la interdependencia dejó de ser visualizada como una realidad operante.

La salida de la pobreza reside en mejorar las capacidades económicas del eslabón más débil de la cadena, los propios pobres. Para ello, se propone la potenciación de los recursos del capital social y activos humanos de las familias pobres, generar capacidades de realización de emprendimientos microempresariales, o mejorando las capacidades de ofrecerse "activamente" como fuerza de trabajo disponible para cualquier trabajo en cualquier condición. La mejora en capital social y humano contribuiría para que los propios pobres se beneficiaran de las oportunidades del mercado.

Esta nueva concepción establece que el problema está en los individuos que por distintos motivos han quedado fuera del sistema. La respuesta escogida ha sido la transferencia de contenidos simbólicos para volver a integrarlos; en otras palabras, si la culpa no es de ellos, sí lo es la causa.

Bajo estas premisas, los programas apuntan al alcanzar transformaciones en los comportamientos de la población beneficiaria con la finalidad de mejorar sus posibilidades de inserción en el mercado, espacio éste que aparece naturalizado como escenario donde se procesa la verdadera integración social. 
La política social del estado de bienestar, tanto aquélla que fue reconocida dentro del campo de las políticas sociales como aquellas intervenciones del estado no identificadas dentro de este campo, regulaciones, reglamentaciones, inversión directa, etc. se caracterizaron por su eficacia política, por su propia naturaleza impactaba positivamente en, lo que podemos llamar, aspectos subjetivos y objetivos, simultáneamente operaban en el terreno del reconocimiento y de la distribución.

En otros términos, operaba sobre el trabajador en tanto individuo organizado y por lo tanto inmediatamente solidario, los beneficios obtenidos eran visualizados por el colectivo como conquista de la acción colectiva, mejoraban de manera inmediata el acceso al bienestar de la población en su conjunto, la propia dinámica social que desarrollaban generaba una amplia participación social y ampliación de la democracia. Es notable que la ofensiva generalizada sobre este estado no se procesó pacíficamente y precisó del autoritarismo en las economías centrales (el ejemplo más paradigmático es el de la dama de hierro Margaret Tatcher) y dictaduras criminales en el tercer mundo (Netto, 1992).

En contraposición, las nuevas políticas sociales implementadas en los años 1990 precisan para su legitimación social todo un aparato de marketing asociado, una escuela pública no precisaba más que un número y un nombre que la identificara (en el caso uruguayo, generalmente es el nombre de un país o un héroe nacional o latinoamericano) mientras que el análisis de los nombres de los nuevos programas sociales bien podría merecer un estudio semiológico. Son intervenciones que precisan de todo un aparato retórico para proteger a sus beneficiarios de los aspectos "vergonzantes" de este tipo de intervenciones: estigmatización, dependencia, desestimulación para el trabajo etc. se repiten como fenómenos asociados a este tipo de intervenciones (al respecto son interesantes las constataciones contenidas en Uga, 2004).

La propia dinámica de este tipo de intervenciones trae aparejado procesos de des-socialización, mientras que en los objetivos buscan reafirmar la integración social, la participación, la solidaridad etc. la propia implementación supone de manera inmediata la individualización, no solo por el 
hecho de que desconocen, en general, las causas sociales de los problemas sobre los que pretenden intervenir, sino y sobre todo porque la propia implementación implica la individualización de los implicados (Rosanvallon, 2011) que aparecen frente al resto de la población, en el mejor de los casos, como dignos de piedad, cuando no sospechados de abusivos, dependientes de la asistencia y posibles responsables de la inseguridad.

Es notable el fracaso de estos programas en la búsqueda de amortiguar la crisis de integración social que se procesa inexorablemente a partir del desmonte de los estados sociales. La participación y organización social de los "excluidos" no ha generado ningún efecto duradero y los agonistas de estos programas acaban siendo responsabilizados por su no participación en espacios de participación generados desde lo alto. La estigmatización de esta población es un dato factual a pesar de toda la parafernalia de discursos "políticamente correctos" que buscan amortiguarla, esto no significa de ningún modo que el desmontaje sea una solución, la no intervención en este contexto sería simplemente criminal, de hecho uno de los que deben ser denunciados es el carácter minimalista de este tipo de intervención, la que pretende analizarse desde esta ponencia invierte apenas el 0,48 \% del PBI, el desmontaje de los estados sociales hace inevitable este tipo de intervención social (Netto, 2012).

La crisis de integración social que padecen las sociedades contemporáneas es resultado directo de una regulación mercado céntrica. De ningún modo la reducción de las intervenciones del Estado pueden tener un efecto positivo, por el contrario, una sociedad mercado céntrica es una sociedad donde la única institución fuerte y saludable es el mercado mientras que el resto de las instituciones padecen un deterioro permanente, y lo más dramático es que cuando se evalúa el funcionamiento de las instituciones acaba por utilizarse parámetros mercantiles, la legitimidad de las instituciones pierde parámetros propios y es colonizada por parámetros mercantiles, verbigracia la educación es mala porque no forma para el mercado laboral (Bentura; Vecinday, 2009).

Recebido em 8/8/2017 - Aprovado em 23/10/2017 


\section{Referencias bibliográicas}

ANTUNES, R Diez tesis sobre el trabajo del presente (y el futuro del trabajo). En Trabajo, empleo, calificaciones profesionales, relaciones de trabajo e identidades laborales / compilado por Julio César Neffa; Enrique de la Garza Toledo; Leticia Muñiz Terra. Consejo Latinoamericano de Ciencias Sociales - CLACSO: CAICyT. Buenos Aires, 2009.

. Adeus ao trabalho? Ensaio sobre as metamorfoses e a centralidade do mundo do trabalho. São Paulo: Cortez Editora, 1995.

ASTORI, D. Los resultados económicos del proceso. Revista universitaria Dialogo Montevideo, 1983.

BAUMAN, Z. La modernidad líquida. Buenos Aires: Paidós, 2002.

BENTURA, José Pablo. La cuestión social en la era progresista. Propuesta de una tipología para su comprensión. Tesis doctoral. Facultad Latinoamericana de Ciencias Sociales (sede argentina). Buenos Aires 2011.

BENTURA, José Pablo; VECINDAY, María Laura. La evaluación "tautológica” de los programas de transferencia de renta condicionada. Revista de Politicas Públicas, Programa de Pós-graduação em Políticas Públicas. Universidade Federal do Maranhão. São Luiz de Maranhão 2013.

BECK, U. La sociedad del riesgo. Hacia una nueva modernidad. Buenos Aires: Paidós, 1998.

CAETANO, G. Introducción general. Marco histórico y cambio político en dos décadas de democracia. De la transición democrática al gobierno de izquierda. In: CAETANO, G. (comp.) 20 años de democracia. Uruguay 1985-2005: miradas múltiples. Montevideo: Taurus, 2005.

CALVO, J. J.; PELLEGRINO, A. Veinte años no es nada... In: CAETANO, G. (comp.). 20 años de democracia. Uruguay 1985-2005: miradas múltiples. Montevideo: Taurus, 2005.

CANDIA, José Miguel. Exclusión y pobreza. La focalización de las políticas sociales. Revista Nueva Sociedad, n. 156. México 1998.

CASTEL, R. Las metamorfosis de la Cuestión Social. Una crónica del salariado. Buenos Aires: Paidós, 1997. 
CRESPO, E, REVILA, JC y SERRANO, A. Del Gobierno del trabajo al gobierno de las voluntades: El caso de la activación. Ed, Psicoperspectivas. V. VIII, N. 2. 2009. Disponible en: <http://www.psicoperspectivas.cl/index.php/psicoperspectivas/issue/ view/10>. Acesso em:

FILGUEIRA, Fernando. El nuevo modelo de prestaciones sociales en América Latina, eficiencia, residualismo y ciudadanía estratificada. In: ROBERTS, Bryan (Editor) Ciudadanía y Política Social. Flacso. Costa Rica 1998.

DURKHEIM. E. La división del trabajo social. Madrid: Akal, 2001.

FILGUEIRA, Fernando. El nuevo modelo de prestaciones sociales en América Latina, eficiencia, residualismo y ciudadanía estratificada. En: Bryan Roberts (Editor) Ciudadanía y Política social. Costa Rica: Ed. Flacso, 1998.

FILGUEIRA et al. Los dos ciclos del Estado uruguayo en el siglo XX. In: NAHUM, Benjamin; CAETANO, Gerardo (coords.) El Uruguay del siglo XX. La Política. Montevideo: Instituto de Ciencia Política/la Banda Oriental, 2003.

GIDDENS, A. El estado del bienestar en una sociedad europea moderna. Disponible en: http://www.uoc.edu/symposia/caixamanresa/jornadaeconomia/esp/giddens.pdf 2004 . Acceso: 23 de nov. de 2014.

GORZ, André. Adeus ao proletariado. Forense. Rio de Janeiro 1982.

GRASSI, Estela. Políticas y problemas sociales en la sociedad neoliberal. La otra década infame (I). Buenos Aires: Espacio Editorial, 2003.

GRASSI, Estela et al. Políticas Sociales. Crisis y ajuste estructural. Buenos Aires: Espacio Editorial, 1994.

HOBSBAWM, Eric. Era dos extremos. O breve século XX 1914-1991. São Paulo: Companhia das Letras, 1995.

HARVEY, D. Condição Pós-Moderna. São Paulo: Loyola, 1992.

HAYEK, Friedrich A. Camino de servidumbre. Madrid: Alianza Editorial, 2006.

HAYEK, F V. (1937) Economics and Knowledge New York: New York University Press. Discurso presidencial al London Economic Club, 10 de noviembre de 1936. Publicado por primera vez en Economía (febrero de 1937). Disponible en: <http:/www.econlib. org/library/NPDBooks/Thirlby/bcthLS3.html\#Hayek>. Acceso en: 
JACOB, R. El Uruguay de Terra. Montevideo: Ediciones de la Banda Oriental, 1983. . Uruguay 1929-1938: Depresión ganadera y desarrollo fabril. Montevideo: Fondo de Cultura Universitaria, 1981.

KAZTMAN, R. Seducidos y abandonados, el aislamiento social de los pobres urbanos. Revista Cepal, 75. Montevideo 2011.

LESSA, S. Trabalho e proletariado no capitalismo contemporâneo. São Paulo: Cortez Editora, 2011.

LOJKINE, J. La revolución informacional. São Paulo: Cortez Editora, 1995

MARX, K. El Capital. Tomo I. México: Fondo de Cultura Económica, 1978.

MARIATTI, A. La atención al desempleo, de la responsabilidad pública a la activación individual. Revista Fronteras No 10. Montevideo 2017.

MIDAGLIA, Carmen. Políticas sociales en el Uruguay recursos institucionales y propuestas para la orientación de políticas. Montevideo: Flacso-Ciesu, 1993.

; ANTIA, Florencia. La izquierda en el gobierno: ¿cambio o continuidad en las políticas de bienestar social? Rev. Uruguaya de Ciencia Política, v. 16, n. 1, p. 131-157. Montevideo, 2007.

MITJAVILA, M. “Globalización, Modernidad e individualización social. "Revista Katalysis". 7, N. 1. Florianópolis 2004.

NETTO, José Paulo. Crise do capital e consequências societárias. Serviço Social e Sociedade, n. 111. Cortez Editora. São Paulo 2012.

. Capitalismo Monopolista e Serviço Social. São Paulo: Cortez Editora, 1996.

OFFE, Claus. Capitalismo desorganizado. Transformações contemporâneas do trabalho e da política. São Paulo: Brasiliense, 1995.

PRZEWORSKI, Adam. Capitalismo e social-democracia. São Paulo: Companhia das Letras, 1995.

RAMBLA, X. Los instrumentos de la lucha contra la pobreza: una revisión de dos tesis sociológicas sobre las estrategias de focalización y activación. Revista Argentina de Sociología. Buenos Aires, 2005.

ROSANVALLON, Pierre. La nueva Cuestión Social. Repensar el Estado providencia. Buenos Aires: Editorial Manantial, 1995. 
SALVIA, A. De marginalidades sociales en transición a marginalidades económicas asistidas. In: BARBA; COHEN (coords.) Perspectivas críticas sobre la cohesión social. Desigualdad y tentativas fallidas de integración social en América Latina. Series CLACSO. Buenos Aires: CLACSO-CROP, 2011.

SANTOS ORTEGA, A.; SERRANO PASCUAL, A. El giro copernicano del desempleo actual. Cuadernos de Relaciones Laborales, 24, n. 2. Disponible en: <http://dialnet. unirioja.es/servlet/articulo?codigo=2235593 2009>. Acceso en: 02/02/2014.

SANZ DE MIGUEL, P. El discurso de la activación dentro de la estrategia europea de empleo: análisis de los marcos interpretativos. Intersticios. Revista Sociológica de Pensamiento Crítico, 2013.

SCHULTZ, T. W. (1992) Restablecimiento del equilibrio económico los recursos humanos en una economía en proceso de modernización. Barcelona: Gedisa, 1992.

SERNA, Miguel. Las políticas de la pobreza en los gobiernos de izquierda del cono sur: de las redes sociales de seguridad a las redes de protección social. Este artículo forma parte de los resultados del Proyecto de investigación "Las políticas sociales de las izquierdas ¿un modelo de desarrollo alternativo?", financiado por el Programa de Becas Gobiernos progresistas en la era neoliberal: estructuras de poder y concepciones de desarrollo en América Latina y el Caribe. CLACSO, 2007.

SERRANO PASCUAL, A. Del desempleo como riesgo al desempleo como trampa: ¿Qué distribución de las responsabilidades plantea el paradigma de la activación propuesto por las instituciones europeas? Cuadernos de Relaciones Laborales, 23, n. 2. Disponible en: $<$ http://revistas.ucm.es/index.php/CRLA/article/view/CRLA0505220219A $>$. Acceso en: $28 / 02 / 2014$.

SADER, Emir; GENTILI, Pablo (orgs.) Pós-neoliberalismo: as políticas sociais e o Estado democrático. São Paulo: Paz e Terra, 1995.

SUPERVIELLE, M y PUCCI, F. El trabajo y las relaciones laborales en el siglo XX. En: El Uruguay del siglo XX. Montevideo: Banda Oriental y Departamento de Sociología de la FCS de la Udelar, 2008.

VV.AA. (Orgs.). Sader, EMIR; Gentili, PABLO; Pós-neoliberalismo as Politicas Sociais e o Estado Democrático. São Paulo: Paz e Terra, 1995. 